\title{
Validation of obesity based on self-reported data in Spanish women participants in breast cancer screening programmes
}

Beatriz Isidoro ${ }^{1,2}$, Virginia Lope ${ }^{1,3}$, Carmen Pedraz-Pingarrón ${ }^{4}$, Francisca Collado-García ${ }^{5}$, Carmen Santamariña ${ }^{6}$, Pilar Moreo ${ }^{7}$, Carmen Vidal ${ }^{8}$, María Soledad Laso ${ }^{9,10}$, Milagros García-Lopez ${ }^{3,11}$ and Marina Pollán ${ }^{1,3^{*}}$

\begin{abstract}
Background: Measurement of obesity using self-reported anthropometric data usually involves underestimation of weight and/or overestimation of height. The dual aim of this study was, first, to ascertain and assess the validity of new cut-off points, for both overweight and obesity, using self-reported Body Mass Index furnished by women participants in breast cancer screening programmes, and second, to estimate and validate a predictive model that allows recalculate individual BMI based on self-reported data.
\end{abstract}

Methods: The study covered 2927 women enrolled at 7 breast cancer screening centres. At each centre, women were randomly selected in 2 samples, in a ratio of 2:1. The larger sample $(n=1951)$ was used to compare the values of measured and self-reported weight and height, to ascertain new overweight and obesity cut-off points with self-reported data, using ROC curves, and to estimate a predictive model of real BMI using a regression model. The second sample $(n=976)$ was used to validate the proposed cut-off points and the predictive model.

Results: Whereas reported prevalence of obesity was $19.8 \%$, measured prevalence was $28.2 \%$. The sensitivity and specificity of this classification would be maximised if the new cut-off points were $24.30 \mathrm{~kg} / \mathrm{m} 2$ for overweight and $28.39 \mathrm{~kg} / \mathrm{m} 2$ for obesity. The probability of classifying women correctly in their real weight categories on the basis of these points was $82.5 \%$ in the validation sample. Sensitivity and specificity for determining obesity using the new cut-off point in the validation sample were $90.0 \%$ and $92.3 \%$ respectively. The predictive model for real BMI included the self-reported BMI, age and educational level (university studies vs lower levels of education). This model succeeded in correctly classifying $90.5 \%$ of women according to BMI categories, but its performance was similar to that obtained with the new cut-off points.

Conclusions: Quantification of self-reported obesity entails a considerable underestimation of this problem, thereby questioning its validity. The new cut-off points established in this study and the predictive equation both allow for more accurate estimation of these prevalences.

\section{Background}

Obesity, acknowledged as being as the epidemic of the 21st-century in the light of its sharp increase in industrialised countries [1], constitutes a growing health problem $[2,3]$. Obesity is associated with the development of a number of diseases, including breast cancer among post-menopausal women. Moreover, obesity ranks after

\footnotetext{
* Correspondence: mpollan@isciii.es

${ }^{1}$ Cancer and Environmental Epidemiology Unit, National Centre for Epidemiology, Carlos III Institute of Health, Madrid, Spain

Full list of author information is available at the end of the article
}

smoking as the second leading risk factor for all-cause cancer [4]. In Spain, the prevalence of obesity among subjects aged over 18 years, obtained on the basis of self-reported data, stands at 16\% [5] with evidence of a growing trend over the last two decades in men and women alike [6].

The collection of self-reported weight and height data by means of personal interviews, telephone calls or selfadministered questionnaires, is frequently used in epidemiological studies to ascertain the prevalence of obesity, due mainly to their speed and low cost. Nevertheless,

\section{() Biomed Central}

(c) 2011 Isidoro et al; licensee BioMed Central Ltd. This is an Open Access article distributed under the terms of the Creative Commons Attribution License (http://creativecommons.org/licenses/by/2.0), which permits unrestricted use, distribution, and reproduction in any medium, provided the original work is properly cited. 
many authors have shown that self-reported weight and height values do not allow for a correct estimate of the prevalence of obesity, which leads to an underestimation of weight and/or overestimation of height, and, by extension, to an underestimation of Body Mass Index (BMI) [7-10]. In Spain, breast cancer screening programmes collect data on the principal risk factors for this tumour, including age, family history, main reproductive variables and, in many cases, self-reported weight and height.

There are studies in the literature which have performed corrections of self-reported BMI by developing equations or predictive models based on subjects' individual characteristics $[8,11]$. Knowledge of the factors that determine the underestimation of weight and overestimation of height, such as educational level, socioeconomic status or age are useful to correct understimated values [12], providing greater accuracy in estimating the prevalence of obesity and overweight.

Accordingly, the aim of this study was to assess the validity of self-reported anthropometric data furnished by women participants in breast cancer early detection programmes in Spain, propose new cut-off points for defining overweight and obesity categories and build up a predictive model to estimate real BMI from selfreported BMI. Finally, we validated the new cut-off points and the predictive model in an independent sample.

\section{Methods \\ Sample}

This study used the women enrolled in the DDM-Spain (Determinants of Mammographic Density in Spain Determinantes de la Densidad Mamográfica en España) study, the goal of which was to investigate the prevalence of high mammographic density and their determinants in women participants in breast cancer early detection programmes in Spain [13]. Briefly, the study covered 3,574 women aged 45 to 68 years, at 7 screening centres in Aragon, the Balearic Isles, Castile-León, Catalonia, Galicia, Navarre and Valencia, with a minimum of 500 women per centre.

\section{Measure}

Data were collected using a structured epidemiological questionnaire administered by a trained interviewer at the respective screening centres. Among other matters, participants were asked, "Could you tell us approximately how much you weigh?", and, "Could you tell us approximately how tall you are?". On completion of the survey, weight (in $\mathrm{kg}$ ) and height (in $\mathrm{cm}$ ) were measured twice by the interviewers, in accordance with standardised protocols and using identical types of scales and stadiometers at all centres. Where there was a wide divergence between the first two measurements, a $3^{\text {rd }}$ measurement was taken.

Standing height was measured using a stadiometer KaWe PERSON-CHECK ${ }^{\circledR}$ (maximum height $200 \mathrm{~cm}$; precision $0.5 \mathrm{~cm}$ ). Weight was measured using a digital tilt Seca SA $841^{\circledR}$ (maximum weight $140 \mathrm{~kg}$; precision $0.1 \mathrm{~kg}$ ). Participants were requested to remove their shoes and any other heavy items of clothing and/or accessories that might constitute additional weight (coins, keys, etc.). BMI was calculated in accordance with the formula, "weight $(\mathrm{kg}) /$ height $^{2}(\mathrm{~m})$ ", for both real and self-reported measures. Overweight status was defined as BMI of $25-29.99 \mathrm{~kg} / \mathrm{m}^{2}$, and obesity status as $\mathrm{BMI} \geq 30 \mathrm{~kg} / \mathrm{m}^{2}$, in line with the classification proposed by the World Health Organisation [14]. Women without any information on self-reported (643) or measured BMI (2) were excluded from the study.

The total sample (2927) was randomly divided into two groups: $2 / 3$ of the population (1951 women) was allocated to sample I, i.e., the sample to be used for estimating the new cut-off points and the predictive equation. The remaining 1/3 (976 women) was allocated to sample II, reserved to validate the new cut-offs and the predictive model. Seeing as the women came from 7 different geographical settings, the process of random allocation in the established 2:1 ratio to samples I and II was performed separately at each.

Women who agreed to take part in the study signed an informed consent document, giving permission for their data to be included in databases for subsequent processing and analysis. At every phase of the study, respect was had for the basic ethical principles laid down by the prevailing Personal Data Protection Act (Ley Orgánica de Protección de Datos de Carácter Personal) [15]. The study was evaluated and approved by the ethics committee of Carlos III Institute of Health. The principles of the Declaration of Helsinki were respected.

\section{Statistics}

The socio-demographic characteristics of the women in samples I and II were compared using Pearson's chisquared test (for proportions) and Student's $t$ test (for means). Sample I was used to assess the discrepancy between real and self-reported measures using the Student's $t$ test for paired data. To evaluate graphically the agreement between self-reported and real BMI the method of Bland and Altman was used [16]. Factors associated with the difference between measured anthropometric data and self-reported data were identified using regression models taking the difference between real and self-reported BMI as the explanatory variable. Sample I was also used to propose new cut-off points for defining overweight and obesity categories based on self-reported data, using ROC curves. 
We tested the validity of the new cut-off points in the validation sample, by estimating the percentage of correctly classified women and using a test for comparison of proportions to compare this percentage to that estimated on the basis of the traditional cut-off points. The concordance between weight categories according to measured and self-reported BMI under the new cut-off points was calculated by the weighted Kappa Index, using quadratic weights, which improved the degree of concordance established by the linear Kappa Index for ordinal variables, since it takes the distance between disagreements into account. The level of concordance was established using the Altman classification [17], which deems any value above 0.60 as indicative of high concordance.

In a second step, Sample I was used to generate a predictive equation to estimate real BMI in a linear regression model including self-reported BMI and those sociodemographic characteristics that influenced the differences observed between self-reported and real BMI. Women in the validation sample were then classified in the three categories, namely normal weight, overweight and obesity, taking into account their predicted BMI values. The performance of the model was assessed considering, as before, the percentage of women correctly classified, the weighted Kappa Index and ROC curves for obesity and overweight.

Statistical significance was set at a $p$-value $<0.05$. All statistical procedures were performed using the Stata statistical software package version 10.0.

\section{Results}

The overall study participation acceptance rate was $74.5 \%$, with the lowest rate being recorded at the centre in Corunna (65\%) and the highest in Zaragoza (84\%). However, $18 \%$ of the women enrolled (643) could not be included in the study due to the fact that they failed to provide information on their height $(81.2 \%)$, their weight $(11.4 \%)$ or both $(7.5 \%)$. Prevalence of obesity was significantly higher in these women than it was among those who were included in the study $(35.8 \%$ versus 28.1\%; $p<0.001$ ).

The socio-demographic characteristics of the women in the study are shown in Table 1, with no significant differences being found between the study and validation samples.

\section{Sample I: establishment of new cut-off points $y$ estimation of predictive model}

On average, measured weights were significantly greater than self-reported weights (Table 1). The oppposite is true regarding height, for which real measurements were significantly lower than self-reported ones. The mean difference between real and self-reported
Table 1 Socio-demographic characteristics of the women in samples I (study sample) and II (validation sample)

\begin{tabular}{|c|c|c|c|}
\hline \multirow{3}{*}{ Variables } & Sample I & Sample II & \multirow{3}{*}{$\begin{array}{c}p- \\
\text { value }\end{array}$} \\
\hline & $\mathrm{N}=1951$ & $N=976$ & \\
\hline & n (\%) & n (\%) & \\
\hline \multicolumn{4}{|l|}{ Age (in years) } \\
\hline $45-49$ & $327(16.8)$ & $135(13.8)$ & \\
\hline $50-54$ & $561(28.8)$ & $287(29.4)$ & \\
\hline $55-59$ & $537(27.5)$ & $287(29.4)$ & \\
\hline$\geq 60$ & $526(27.0)$ & $267(27.4)$ & 0.2135 \\
\hline Self-reported BMI, mean (SD) & $26.6(4.5)$ & $26.5(4.6)$ & 0.5737 \\
\hline Self-reported weight & $67.1(11.8)$ & $66.9(11.8)$ & 0.6656 \\
\hline Self-reported height & $158.8(6.0)$ & $158.9(6.1)$ & 0.6725 \\
\hline Measured BMI, mean (SD) & $27.8(4.9)$ & $27.8(4.9)$ & 1 \\
\hline Self-reported weight & $68.5(12.2)$ & $68.4(12.2)$ & 0.8344 \\
\hline Self-reported height & $156.9(5.8)$ & $157.0(6.0)$ & 0.6638 \\
\hline \multicolumn{4}{|l|}{ Overweight } \\
\hline Based on self-reported BMI & 772 (39.6) & $342(35.0)$ & 0.0194 \\
\hline Based on measured BMI & $831(42.6)$ & $412(42.2)$ & 0.8755 \\
\hline \multicolumn{4}{|l|}{ Obesity } \\
\hline Based on self-reported BMI & $387(19.8)$ & $206(21.1)$ & 0.4487 \\
\hline Based on measured BMI & $550(28.2)$ & $270(27.7)$ & 0.7983 \\
\hline \multicolumn{4}{|l|}{ Screening centre } \\
\hline Corunna (La Coruña) & $309(15.8)$ & $168(17.2)$ & \\
\hline Barcelona & $255(13.1)$ & $129(13.2)$ & \\
\hline Burgos & $268(13.7)$ & $116(11.9)$ & \\
\hline Palma de Mallorca & $336(17.2)$ & $174(17.8)$ & \\
\hline Pamplona & $237(12.2)$ & $114(11.7)$ & \\
\hline Zaragoza & 239 (12.3) & $120(12.3)$ & \\
\hline Valencia & $307(15.7)$ & $155(15.9)$ & 0.8418 \\
\hline \multicolumn{4}{|l|}{ Town size } \\
\hline$<200,000$ & $867(44.4)$ & $430(44.1)$ & \\
\hline $200,000-300,000$ & $517(26.5)$ & $272(27.9)$ & \\
\hline$>300,000$ & $567(29.1)$ & $274(28.1)$ & 0.7064 \\
\hline \multicolumn{4}{|l|}{ Marital status } \\
\hline Single & $111(5.7)$ & $63(6.5)$ & \\
\hline Married/stable couple & $1541(79.9)$ & 779 (79.8) & \\
\hline Separated/divorced & 167 (8.6) & $75(7.7)$ & \\
\hline Widow & $132(6.8)$ & $58(5.9)$ & 0.5766 \\
\hline \multicolumn{4}{|l|}{ Menopause } \\
\hline Pre-menopausal & $436(22.4)$ & $204(20.9)$ & \\
\hline Post-menopausal & $1515(77.7)$ & $772(79.1)$ & 0.3982 \\
\hline \multicolumn{4}{|l|}{ Educational level } \\
\hline $\begin{array}{l}\text { Up to junior school-leaving } \\
\text { certificate }\end{array}$ & $1347(69.1)$ & $671(68.8)$ & \\
\hline $\begin{array}{l}\text { Senior school-leaving } \\
\text { certificate }\end{array}$ & $198(10.2)$ & $93(9.5)$ & \\
\hline Vocational training & $185(9.5)$ & $96(9.9)$ & \\
\hline University & $219(11.2)$ & $115(11.8)$ & 0.9141 \\
\hline \multicolumn{4}{|l|}{ Socio-economic level } \\
\hline Very low/low social class & $469(24.0)$ & $223(22.9)$ & \\
\hline Middle social class & $1383(70.9)$ & $689(70.6)$ & \\
\hline High/very high social class & $92(4.7)$ & $60(6.2)$ & 0.2268 \\
\hline
\end{tabular}


measurements was also statistically significant for both weight $(1.41$, SD $2.75, p<0.001)$ and height $(-1.92$, SD $2.68, p<0.001)$. Thirty two percent of women underestimated their weight two or more kilograms, and a 5\% overestimated their height two or more $\mathrm{cm}$. Consequently, self-reported BMI was substantially lower than BMI computed on the basis of measured data (selfreported BMI mean: $26.59 \mathrm{~kg} / \mathrm{m}^{2}$, SD: 4.49 , vs. measured BMI mean: $27.83 \mathrm{~kg} / \mathrm{m}^{2}$, SD: 4.86; $\left.p<0.001\right)$. In total, $52.3 \%$ of women underestimated their BMI one or more points.

Figure 1 shows the correlation between self-reported and measured BMI according to the Bland and Altman method. (Figure 1). The average difference between measured and self-reported BMI among women with normal weight was 0.61 (95\% CI $0.52-0.71$ ), and increased from 1.17 among overweight (95\% CI 1.091.26 ) to 2.03 among obese women (95\% CI 1.88-2.19). Self-reported data thus underestimated the prevalence of obesity $(19.8 \%$ vs. $28.2 \%, p<0.001)$ and, to a lesser extent, that of overweight (39.6\% vs. $42.6 \%)$.

The sensitivity and specificity of self-reported BMI for the obesity classification threshold of $30 \mathrm{~kg} / \mathrm{m}^{2}$ was 68.18 (95\% CI: 64.20-72.17) and 99.14 (95\% CI 98.6399.66), respectively. ROC curve analysis furnished an optimal obesity cut-off point for self-reported BMI of $28.39 \mathrm{~kg} / \mathrm{m}^{2}$, thereby increasing sensitivity $(88.36 ; 95 \%$ CI 85.59-91.13). Specificity was 94.65 (95\% CI $93.43-$ 95.86). The area under the ROC curve improved from 0.84 (95\% CI 0.82-0.86) to 0.92 (95\% CI 0.91-0.93), with this difference proving statistically significant $(p<$ 0.001 ).

In the case of overweight, the original cut-off point of $25 \mathrm{~kg} / \mathrm{m}^{2}$ displayed a sensitivity of $82.6 \%$ (95\% CI: 80.9\%-84.3\%), which improved substantially with the new overweight threshold established at $24.30 \mathrm{~kg} / \mathrm{m}^{2}$, (sensitivity 91.09, 95\% CI 89.55-92.63; specificity 90.18, 95\% CI 87.64-92.71). Nevertheless, the area under the ROC curve increased only discreetly, going from 0.90 (95\% CI 0.88-0.91) to 0.91 (95\% CI 0.89-0.92), with this difference not proving statistically significant $(p=0.161)$.

Factors associated with the difference between measured anthropometric data and self-reported data are shown in Table 2. The underestimation of BMI was more pronounced in older women and in women with higher BMI ( $p=0.013$ and $p<0.001$, respectively). After adjusting by age and measured BMI, educational level was the only sociodemographic variable that proved to contribute to the gap between self-reported and measured values $(p=0.014)$. As it can be seen in Table 2, differences between measured and self-reported BMI were similar among women in the first three categories of education, but those with university studies underestimated their BMI considerably less. Finally, differences between self-reported and measured BMI varied among the screening centres.

A regression model was then fitted to estimate BMI from self-reported data, age and level of education. This last factor was dichotomized considering women without and with university studies. Continuous variables were centred and interactions between these explanatory variables were tested, being none of them statistically significant. Self-reported BMI, age and university studies explained $90.5 \%$ of the variability observed in the measured BMI. The final model was as follows: $\mathrm{BMI}=26.90$ +1.02 (self-reported BMI - 25.64) + 0.04 (age - 55.91) 0.23 (university Studies $=$ yes).

\section{Sample II: validation results}

The validation sample comprised 976 women. The prevalences of obesity and overweight estimated on the basis of measured data were $27.7 \%$ and $42.2 \%$, as compared to $21.1 \%$ and $35.0 \%$ respectively when estimated on the basis of self-reported data.

Figure 2a depicts the distribution by real weight categories according to self-reported BMI, using the traditional (Figure 2a.1) and new cut-off points (Figure 2a.2) and the first two columns in Table 3 compare the performance of self reported BMI with the classification using new cut-offs points. Figure $2 \mathrm{a}$ shows that, whereas using the new cut-off points to ascertain the presence of obesity displayed a sensitivity of $90.0 \%$ (95\% CI 85.8 93.3) and a specificity of $92.3 \%$ (95\% CI 90.1-95.0), using the traditional cut-off points yielded a sensitivity of $64.0 \%$ (95\% CI 61.0-97.1) and a specificity of 96.0\% (95\% CI 94.7-97.3). The proportion of overweight women correctly classified by reference to self-reported BMI also increased when the new cut-off points were used (71.0\%, $95 \%$ CI $68.1-73.9$ vs. $66.0 \%, 95 \%$ CI $63.0-69.0)$. A total of $82.5 \%$ of women were classified correctly in their weight categories, $6.3 \%$ more than when using the traditional cut-off points (Table 3), with this gain being statistically significant $(\mathrm{p}$-value $=0.004)$. In the case of obesity, the positive predictive value was 82.09 (95\% CI 77.56-86.63) and the negative predictive value was 96.03 (95\% CI 94.49-97.57); in the case of overweight, these values were 85.92 (95\% CI 82.09-89.76) and 81.26 (95\% CI 78.15-84.37) respectively. A high degree of concordance was observed between the classification using anthropometric measures and self-reported data with the new cut-off points (weighted kappa of 0.85 ; 95\% CI: $0.82-0.87)$. Finally, there was a statistically significant gain in the discriminative power of the new cut-offs for obesity and for overweight proved by the observed differences in ROC areas (Table 3; $p<0.001$ ).

Regarding the validation of the predictive model, the mean of predicted BMI values was 27.77 (SD 4.62) very similar to the mean of the measured BMI in this group 


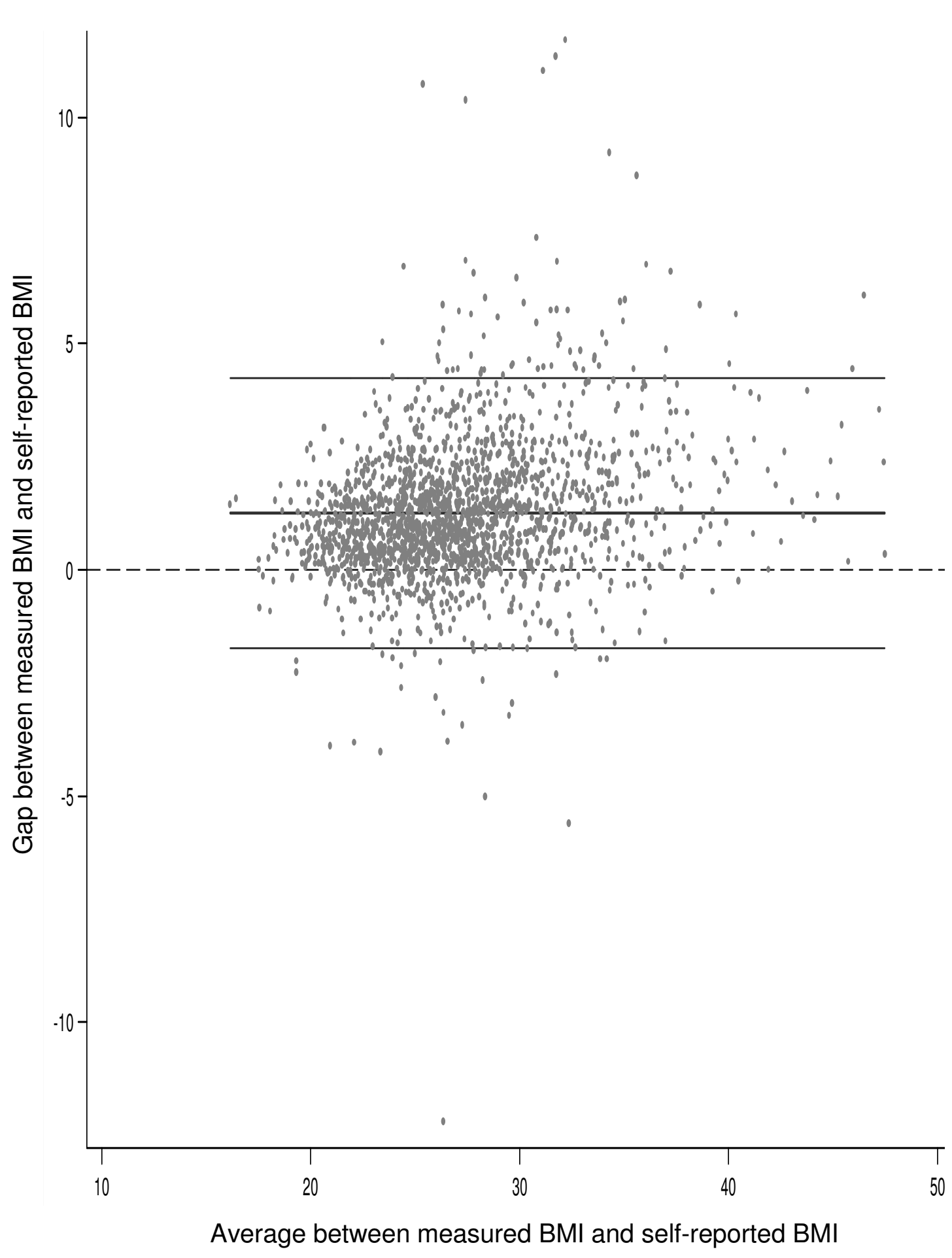

Figure $1 \mathrm{Gap}$ between measured and self-reported BMI compared to the average between measured and self-reported BMI. Bland and Altman method.

of women $($ mean $=27.79 ; \mathrm{SD}=4.92)$. The performance of this model is presented in the last column of Table 3. Using the predicted values yielded by the regression model, the percentage of women correctly classified into their corresponding weight categories was $84.6 \%$, this percentage is not significantly different to that obtained using the new cut-off points (Table 3). The Kappa index presented a non significant increase of a $1 \%$ (Weighted 
Table 2 Factors associated with the difference between measured and self-reported anthropometric data

\begin{tabular}{|c|c|c|c|}
\hline Variables & $\begin{array}{c}\text { Mean } \\
\text { Difference* }\end{array}$ & $95 \% \mathrm{IC}$ & $\begin{array}{c}p- \\
\text { value }^{* *}\end{array}$ \\
\hline \multicolumn{4}{|l|}{ Measured IMC } \\
\hline $\begin{array}{l}\text { Underweight and Normal } \\
\text { weight }\end{array}$ & 0.59 & $0.50-0.69$ & \\
\hline Overweight & 1.17 & $1.09-1.26$ & \\
\hline Obesity & 2.03 & $1.88-2.19$ & $<0.001$ \\
\hline \multicolumn{4}{|l|}{ Age } \\
\hline $45-49$ & 0.98 & $0.83-1.12$ & \\
\hline $50-54$ & 1.02 & $0.89-1.16$ & \\
\hline $55-59$ & 1.32 & $1.19-1.45$ & \\
\hline$\geq 60$ & 1.48 & $1.36-1.59$ & 0.013 \\
\hline \multicolumn{4}{|l|}{ Town size } \\
\hline$>200,000$ & 1.30 & $1.20-1.38$ & \\
\hline $200,000-10,000$ & 1.17 & $1.06-1.28$ & \\
\hline$<10,000$ & 1.28 & $1.01-1.54$ & 0.648 \\
\hline \multicolumn{4}{|l|}{ Marital status } \\
\hline Single & 1.28 & $1.02-1.53$ & \\
\hline Married/stable couple & 1.24 & $1.16-1.32$ & \\
\hline Separated/divorced & 1.19 & $0.97-1.41$ & \\
\hline Widow & 1.38 & $1.12-1.64$ & 0.283 \\
\hline \multicolumn{4}{|l|}{ Menopause } \\
\hline Pre-menopausal & 0.97 & $0.83-1.11$ & \\
\hline Post-menopausal & 1.32 & $1.25-1.40$ & 0.530 \\
\hline \multicolumn{4}{|l|}{ Educational level } \\
\hline $\begin{array}{l}\text { Up to junior school-leaving } \\
\text { certificate }\end{array}$ & 1.29 & $1.20-1.37$ & \\
\hline $\begin{array}{l}\text { Senior school-leaving } \\
\text { certificate }\end{array}$ & 1.34 & $1.11-1.58$ & \\
\hline Vocational training & 1.24 & $1.02-1.46$ & \\
\hline University & 0.93 & $0.77-1.10$ & 0.014 \\
\hline \multicolumn{4}{|l|}{ Socio-economic level } \\
\hline Very low/low social class & 1.26 & $1.11-1.41$ & \\
\hline Middle social class & 1.25 & $1.17-1.33$ & \\
\hline High/very high social class & 1.11 & $0.89-1.34$ & 0.188 \\
\hline \multicolumn{4}{|l|}{ Screening centre } \\
\hline Corunna (La Coruña) & 1.61 & $1.40-1.82$ & \\
\hline Barcelona & 1.23 & $1.06-1.40$ & \\
\hline Burgos & 0.72 & $0.54-0.90$ & \\
\hline Palma de Mallorca & 1.62 & $1.48-1.76$ & \\
\hline Pamplona & 1.59 & $1.41-1.77$ & \\
\hline Zaragoza & 0.58 & $0.42-0.73$ & \\
\hline Valencia & 1.20 & $1.03-1.37$ & $<0.001$ \\
\hline
\end{tabular}

* Measured BMI - Self-reported BMI

** Data are adjusted by age and measured BMI

kappa: 0.86 ; $95 \%$ CI: 0.84 to 0.88 ). The area under the ROC curve also were very similar to those obtained with the proposed cut-offs (Figure 2b).

\section{Discussion}

Our results confirm the underestimation of prevalence of overweight and obesity when self-report measures are used in Spanish women attending breast cancer screening programs. Validation of self-reported data in this population had not been previously reported. Prevalence of obesity calculated on the basis of self-reported values was $19.8 \%$, which differed substantially from the prevalence of real obesity, which stood at $28.2 \%$. In the latest European Health Survey (Encuesta Europea de Salud 2009), prevalence of self-reported obesity among Spanish women aged $45-64$ years was $17.3 \%$ [5]. Our sample of women thus displayed high obesity indices.

Techniques of collecting self-reported data have also been analysed by some authors. As compared to personal interviews, the telephone interview has been frequently associated with larger underestimates of prevalence of obesity [18]. The impossibility of an interviewer verifying the information furnished by telephone might account for this phenomenon. Nevertheless, Galán et al. [19] highlighted the fact that the results of telephone and "face-to-face" interviews were very similar. At all events, the heterogeneity observed reveals the importance of validating self-reported information, so that the reliability of the data is ensured.

Many studies have observed substantial differences between measured and self-reported values, though the magnitude of the discrepancy is variable $[7,8,10,20,21]$. In our study, more than $50 \%$ of women underestimated their BMI one or more points, with these results once again being higher than those reported by other authors $[7,8]$. Among the factors that explain this difference are measured weight and height, since persons with elevated weight and short stature tend to underestimate their BMI, probably due to personal desire of thinner and more slender body image, especially in women $[9,22]$. In line with other studies, we observed a tendency to underestimate BMI with an increase in women's age $[10,23]$ and a more accurate self-reported BMI in women with university studies [6,24]. Other factors, such as size of municipality, marital status or socio-economic level, did not significantly influence the differences observed between measured and self-reported BMI. However, there was substantial heterogeneity between screening centres regarding the amount of underreporting, something that may be related with other social or cultural characteristics not considered in our study [9.12].

Although many studies confirm the underestimation inherent in self-reported data, few provide the possibility of using new cut-off points when it comes to using selfreport measures. In our study, despite the fact that the specificity of self-reported BMI was good (99\%), there was clearly insufficient capacity to ascertain obesity status (sensitivity of 68.2\%). Similar findings about the new cut-off point have been reported by other studies $[10,25]$. Dauphinot et al. [7] propose a new obesity cut- 


\section{a) Distribution or women acording to real and self-reported BMI (Validation sample)}
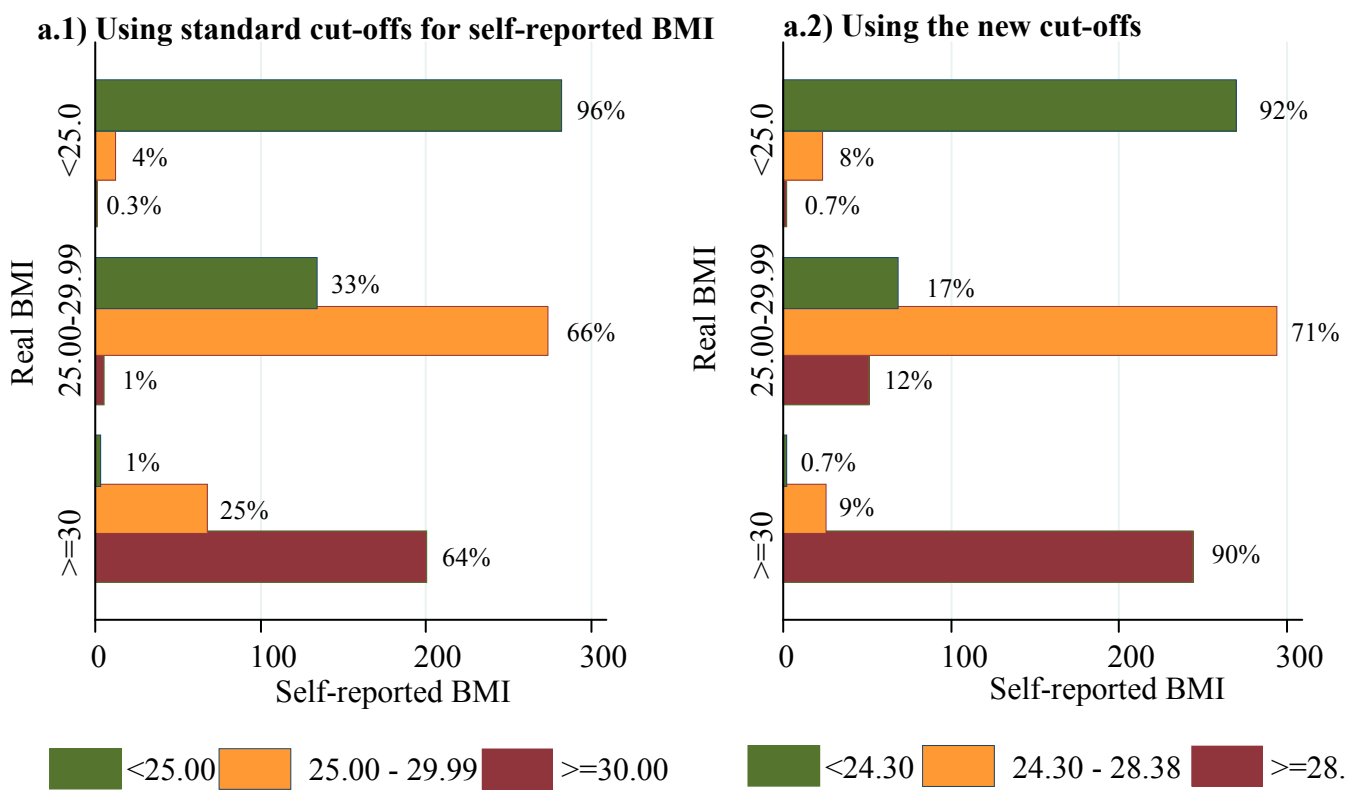

\section{b) ROC curves for obesity \& overweight (Validation sample )}

b.1) Obesity

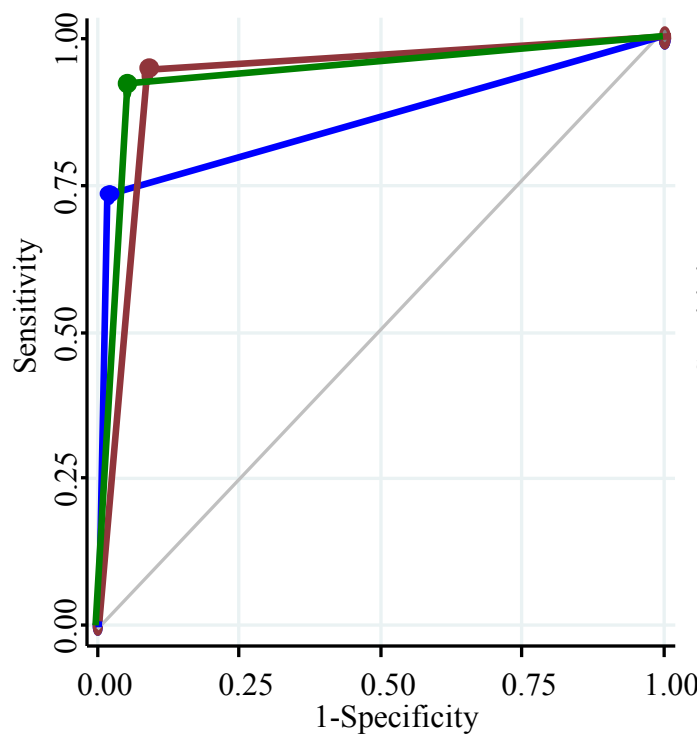

b.2) Overweight

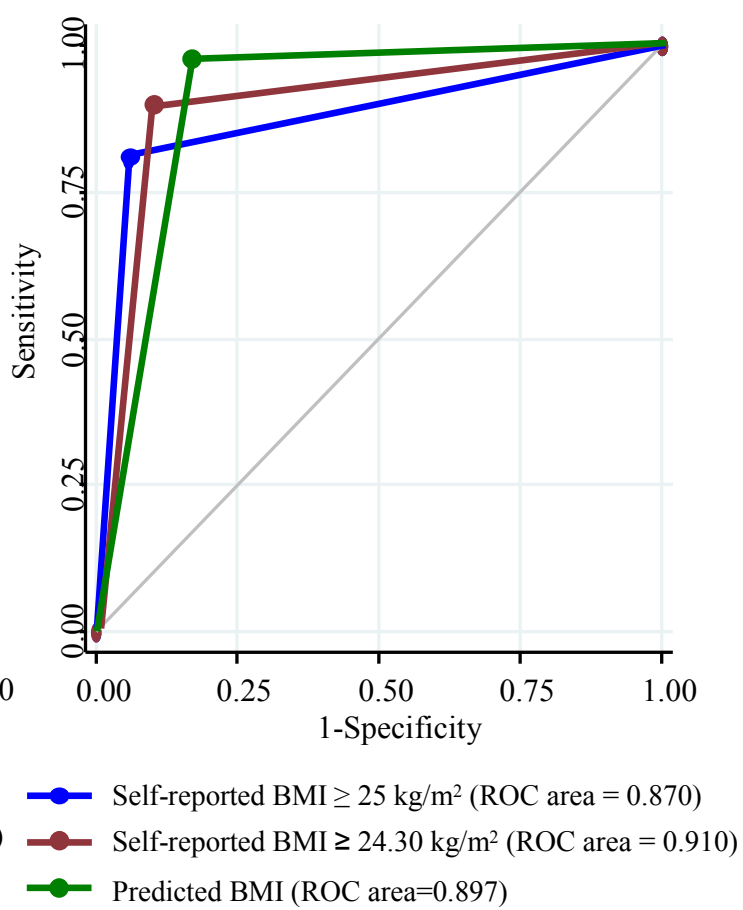

Figure 2 a) Classification of women in the validation sample using self-reported data and traditional cut-off points (left), and new cutoff points (right). b) ROC curves for obesity (left) and overweight (right) in the validation sample using self-reported data with traditional cut-off points, those estimated in our study and predicted BMI.

off point of $29.2 \mathrm{~kg} / \mathrm{m}^{2}$, higher than that obtained by us, though it is important to highlight the difference in the prevalence of obese women that separates the two samples. Another fact established by our study is the high degree of concordance between weight categories achieved when using measured BMI and self-reported 
Table 3 Performance of self-reported BMI, self-reported BMI using the new cut-offs and the predictive regression model in the validation sample

\begin{tabular}{llcc}
\hline & Self reported BMI & Using the new cut-offs & Regression model \\
\hline \% correctly classified $(95 \% \mathrm{Cl})$ & $76.2 \%(73.4-78.9)$ & $82.5 \%(79.9-84.8)$ & $84.6 \%(82.2-86.8)$ \\
Weighted kappa (95\% Cl) & $0.79(0.77-0.82)$ & $0.85(0.82-0.87)$ & $0.86(0.84-0.88)$ \\
ROC Area Obesity (95\% Cl) & $0.87(0.84-0.89)$ & $0.91(0.89-0.93)$ & $0.92(0.89-0.94)$ \\
ROC Area Overweight (95\% Cl) & $0.87(0.85-0.89)$ & $0.91(0.89-0.93)$ & $0.90(0.88-0.92)$ \\
\hline
\end{tabular}

BMI with the new cut-off points. It is greater than that found in similar analyses $[20,25]$. This degree of agreement was also confirmed in our study with the validation sample.

Other studies have previously indicated that deviations in self-reported data depend on demographic, cultural, social and health characteristics of a population at any given time [9.12]. Therefore, we tried to develop a predictive model from self-reported values, with an account of some of these factors, such as age and educational degree. Bolton-Smith et al. [8] proposed a model which is very consistent with that presented here, also including age and self-reported weight and height. Nevertheless, in our case our model did not perform better than the simple adoption of the new cut-offs.

Our study sought to quantify the degree to which obesity was underreported by women participants in breast cancer screening programmes in Spain. Obesity is a risk factor for breast cancer in postmenopausal women, so that many of the screening programmes record weight and height reported by women outpatients undergoing screening mammography. The newly proposed cut-off points could be useful in the context of such programmes. It is important to bear in mind, however, that this study included women from only 7 screening centres, which, albeit situated in different geographical settings, might not adequately represent the variability of our target population. Our study's principal limitation stems from the selection of the study sample. On the one hand, subjects had to agree to participate, so that self-selection could threaten the generalisability of the results; and on the other, the prevalence of obesity among the women who were not included in the study due to failure to furnish anthropometric data, was significantly higher than that among the women who were included (35.8 vs $28.1 \% ; p<0.001$ ), which suggests that women with larger BMI were underrepresented in our study. Older women, women with higher measured BMI, women with lower education and women living in rural areas were less able to provide the necessary information to compute their BMI. Interestingly, in most cases $(81.2 \%$ of women without self-reported BMI) answered the question regarding their weight but did not know their height, 73 women $(11.4 \%)$ reported their height but not their weight and only $7 \%$ of them did not provided any information. Taking these data into account it seems that younger women, urban women and women with a higher educative level are more able to report their height and probably also know more about BMI as an overall measure of obesity.

The applicability of the new cut-off points and the proposed predictive model to other populations must be approached with care. Our study included a variety of screening centres across the country, providing an overall picture regarding the underestimation of BMI and the factors associated with it. However, differences between centers in our study were not fully explained by the heterogeneous distribution of age and other explanatory variables among them. To what extent these differences are related to unmeasured socio-demographic or cultural characteristics or reflect differences in the way the study was carried out is impossible to know. Given the geographical dispersion among centers, a different interviewer was used in each of them. These women were trained by the study coordinator who also periodically supervised their work. However, in spite of the training, it is possible that part of the heterogeneity among screening centres could be caused by differences in the way interviewers gathered information or even weighted and measured the participants. In summary, the validity of our results should be explored before being applied to other centres.

Despite these limitations and having regard to the degree of underreporting observed, the newly proposed cut-off points could nevertheless prove useful for ascertaining overweight and obesity in women attending screening programmes. Obesity is a known risk factor for many chronic diseases [26-28], including breast cancer among post-menopausal women [29]. The high prevalence of obesity detected among the women in our study makes them a risk group to be borne in mind in prevention programmes. Visit to the screening centre could well be a useful time to raise women's awareness as to overweight-related problems and motivate them to achieve a healthier BMI.

\section{Conclusions}

The results of our study confirm the underestimation of obesity in Spanish women attending breast cancer screening when self-reported data are used, and suggest 
the possibility of using new cut-off points to assess the presence of overweight and obesity on the basis of this type of information. Enhancing the sensitivity of the measure would serve to provide more realistic information on the magnitude of the problem of obesity. In view of the high prevalence of obesity detected by us, peri- and post-menopausal women who attend breast cancer screening constitute a risk group.

\section{Acknowledgements}

This study was supported by the Research Grant FIS PI060386 from Spain's Health Research Fund (Fondo de Investigación Sanitaria); the EPY 1306/06 Collaboration Agreement between Astra-Zeneca and the Carlos III Institute of Health (Instituto de Salud Carlos III); and a grant from the Spanish Federation of Breast Cancer patients (FECMA 485 EPY 1170-10). Other members of DDM-Spain: Beatriz Pérez-Gómez, Nuria Aragonés, Gonzalo López Abente, Anna Cabanes, Francisco Casanova, Isabel González Román, Carmen Sánchez-Contador, Jose Antonio Vázquez-Carrete, Ana Belén Fernández, Montserrat Corujo, María Pilar Moreno, Soledad Abad, Mercé Peris, Dolores Salas-Trejo, Josefa Miranda-García, Manuela Alcaraz, Francisco Ruiz-Perales, Nieves Ascunce, María Ederra, Jesús Vioque.

\section{Author details}

${ }^{1}$ Cancer and Environmental Epidemiology Unit, National Centre for Epidemiology, Carlos III Institute of Health, Madrid, Spain. ${ }^{2}$ Department of Preventive Medicine, Puerta de Hierro Majadahonda University Teaching Hospital, Madrid, Spain. ${ }^{3}$ Consortium for Biomedical Research in Epidemiology \& Public Health (CIBER en Epidemiología y Salud Pública CIBERESP), Spain. ${ }^{4}$ Castile-León Breast Cancer Screening Programme, General Directorate of Public Health (Gerencia Regional de Salud - SACyL), CastileLeón, Spain. ${ }^{5}$ Balearic Islands Breast Cancer Screening Programme, Health Promotion for Women and Children, General Directorate of Public Health \& Participation, Regional Authority for Health \& Consumer Affairs, Balearic Islands, Spain. ${ }^{6}$ Galician Breast Cancer Screening Programme, Galician Regional Health Authority, Pamplona, Spain. ${ }^{7}$ Aragon Breast Cancer Screening Programme, Aragon Health Service, Zaragoza, Spain. ${ }^{8}$ Cancer Prevention and Control Unit, Catalonian Institute of Oncology (Institut Català d'Oncologia-ICO), Barcelona, Spain. 'Valencian Breast Cancer Screening Programme, General Directorate of Public Health, Valencia, Spain. ${ }^{10}$ Public Health Research Centre (Centro Superior de Investigación en Salud Pública -CSISP), Valencia, Spain. ${ }^{11}$ Navarre Breast Cancer Screening Programme, Public Health Institute, Pamplona, Spain.

\section{Authors' contributions}

$\mathrm{BI}$ and VL: Study design, analysis and interpretation of results, and draft the manuscript. CPP, FCG, CS, PM, CV, MSL and MGL: Study design, datacollection and critical review of the manuscript (senior screeningprogramme research). MP: Study design, design of research, analysis and interpretation of results, contribution to manuscript writing and review it for important content (senior researcher of the team). All the authors read and approved the final manuscript.

\section{Competing interests}

The authors declare that they have no competing interests.

Received: 22 July 2011 Accepted: 30 December 2011 Published: 30 December 2011

\section{References}

1. WHO/FAO: Joint Who/Fao Expert Consultation on Diet, Nutrition and the Prevention of Chronic Diseases, Diet, Nutrition and the Prevention of Chronic Diseases: Report of a Joint Who/Fao Expert Consultation Geneva: WHO; 2003.

2. Bender R, Trautner C, Spraul M, Berger M: Assessment of excess mortality in obesity. Am J Epidemiol 1998, 147:42-48.

3. Flegal KM, Graubard BI, Williamson DF, Gail MH: Excess deaths associated with underweight, overweight, and obesity. JAMA 2005, 293:1861-1867.
4. Whitlock G, Lewington S, Sherliker P, Clarke R, Emberson J, Halsey J, et al: Body-mass index and cause-specific mortality in 900000 adults: collaborative analyses of 57 prospective studies. Lancet 2009, 373:1083-1096

5. Ministerio de Sanidady Política Social: Encuesta Europea de Salud 2009 Madrid 2009 [http://www.msps.es/gl/estadEstudios/estadisticas/ EncuestaEuropea/].

6. Gutiérrez-Fisac JL, Regidor E, Banegas B Jr, Rodríguez AF: The size of obesity differences associated with educational level in Spain, 1987 and 1995/97. J Epidemiol Community Health 2002, 56:457-460.

7. Dauphinot V, Wolff H, Naudin F, Guéguen R, Sermet C, Gaspoz JM, et al: New obesity body mass index threshold for self-reported data. $J$ Epidemiol Community Health 2009, 63:128-132.

8. Bolton-Smith C, Woodward M, Tunstall-Pedoe H, Morrison C: Accuracy of the estimated prevalence of obesity from self reported height and weight in an adult Scottish population. J Epidemiol Community Health 2000, 54:143-148.

9. Niedhammer I, Bugel I, Bonenfant S, Goldberg M, Leclerc A: Validity of selfreported weight and height in the French GAZEL cohort. Int J Obes Relat Metab Disord 2000, 24:1111-1118.

10. Nyholm M, Gullberg B, Merlo J, Lundqvist-Persson C, Rastam L, Lindblad U: The validity of obesity based on self-reported weight and height: Implications for population studies. Obesity 2007, 15:197-208.

11. Pirie $P$, Jacobs D, Jeffery $R$, Hannan P: Distortion in self-reported height and weight data. J Am Diet Assoc 1981, 78:601-606.

12. Paeratakul S, White MA, Williamson DA, Ryan DH, Bray GA: Sex, race/ ethnicity, socioeconomic status, and BMI in relation to self-perception of overweight. Obes Res 2002, 10:345-350.

13. Cabanes A, Pastor R, García-López M, Pedraz-Pingarrón C, SanchezContador C, Vazquez-Carrete JA: Alcohol, tobacco, and mammographic density: a population-based study. Breast Cancer Res Treat 2011, 129:135.

14. WHO: Consultation on Obesity: Obesity: Preventing and Managing the Global Epidemic. Report No.: 894. Geneva: World Health Organization; 2000.

15. Ley Orgánica 15/1999, de 13 de diciembre, de Protección de Datos de Carácter Personal. Boletín Oficial del Estado, España, 14 de diciembre de 1999, núm. 298 43088-43099.

16. Bland JM, Altman DG: Statistical methods for assessing agreement between two methods of clinical measurement. Lancet 1986, 1:307-310.

17. Altman DG: Practical Statistics for Medical Research New York: Chapman and Hall; 1991, 20-37.

18. Ezzati M, Martin H, Skjold S, Vander HS, Murray CJ: Trends in national and state-level obesity in the USA after correction for self-report bias: analysis of health surveys. J R Soc Med 2006, 99:250-257.

19. Galan I, Rodriguez-Artalejo F, Zorrilla B: Telephone versus face-to-face household interviews in the assessment of health behaviors and preventive practices. Gac Sanit 2004, 18:440-450.

20. Alvarez-Torices JC, Franch-Nadal J, Alvarez-Guisasola F, Hernandez-Mejia R, Cueto-Espinar A: Self-reported height and weight and prevalence of obesity Study in a Spanish population. Int J Obes Relat Metab Disord 1993, 17:663-667.

21. Hill A, Roberts J: Body mass index: a comparison between self-reported and measured height and weight. J Public Health Med 1998, 20:206-210.

22. Nieto-Garcia FJ, Bush TL, Keyl PM: Body mass definitions of obesity: sensitivity and specificity using self-reported weight and height. Epidemiology 1990, 1:146-152.

23. Madrigal H, Sanchez-Villegas A, Martínez-González MA, Kearney J, Gibney MJ, Irala J, et al: Underestimation of body mass index through perceived body image as compared to self-reported body mass index in the European Union. Public Health 2000, 114:468-473.

24. García-Mendizábal MJ, Carrasco JM, Pérez-Gómez B, Aragonés N, GuallarCastillón P, Rodriguez-Artalejo $F$, et al: Role of educational level in the relationship between Body Mass Index (BMI) and health-related quality of life (HRQL) among rural Spanish women. BMC Public Health 2009, 30(9):120.

25. Quiles IJ, Vioque J: Validity of notified anthropometric data for determining the prevalence of obesity. Med Clin (Barc) 1996, 106:725-729.

26. Kopelman PG: Obesity as a medical problem. Nature 2000, 404:635-643.

27. Calle EE, Kaaks R: Overweight, obesity and cancer: epidemiological evidence and proposed mechanisms. Nat Rev Cancer 2004, 4:579-591. 
28. Ferrannini E, Natali A, Bell P, Cavallo-Perin P, Lalic N, Mingrone G: Insulin resistance and hypersecretion in obesity. European Group for the Study of Insulin Resistance (EGIR). J Clin Invest 1997, 100:1166-1173.

29. World Cancer Research Fund/American Institute for Cancer Research: Food, Nutrition, Physical Activity, and the Prevention of Cancer: a Global Perspective Washington: AICR; 2007.

\section{Pre-publication history}

The pre-publication history for this paper can be accessed here: http://www.biomedcentral.com/1471-2458/11/960/prepub

doi:10.1186/1471-2458-11-960

Cite this article as: Isidoro et al: Validation of obesity based on self-

reported data in Spanish women participants in breast cancer

screening programmes. BMC Public Health 2011 11:960.

Submit your next manuscript to BioMed Central and take full advantage of:

- Convenient online submission

- Thorough peer review

- No space constraints or color figure charges

- Immediate publication on acceptance

- Inclusion in PubMed, CAS, Scopus and Google Scholar

- Research which is freely available for redistribution

Submit your manuscript at www.biomedcentral.com/submit 